\title{
Splenic Rupture by Tubular Drain in a Patient with Necrotizing Pancreatitis
}

\author{
Sílvio José de Lucena Dantas ${ }^{1}$, Senival Alves de Oliveira-Júnior ${ }^{2}$, Rielly de Sousa e Silva ${ }^{2}$, Arnaldo Costa de \\ Medeiros-Junior ${ }^{2}$, Sarah Hulliane Freitas Pinheiro de Paiva ${ }^{2}$, Artur de Lemos Campos ${ }^{2}$, Manoel Crizanto das \\ Neves-Neto ${ }^{2}$, José Saint-Clair de Sousa Tôrres-Filho² and Irami Araújo-Filho ${ }^{3 *}$ \\ ${ }^{1}$ General Surgeon; Full member and Expert of the Brazilian Federation of Gastroenterology, of the Brazilian Society of Parenteral and Enteral Nutrition \\ and of the Brazilian College of Digestive Surgery, South America
}

${ }^{2}$ Undergraduate medical student, Potiguar University - Laureate International Universities - Natal, Rio Grande do Norte, South America

${ }^{3}$ Full Professor of the Department of Surgery, PhD in Health Sciences, Potiguar University - Laureate International Universities, Natal, Rio Grande do Norte, South America

Submission: February 26, 2017; Published: March 14, 2017

*Corresponding author: Irami Araújo Filho, Full Professor of the Department of Surgery, PhD in Health Sciences. Potiguar University - Laureate International Universities, Natal, Rio Grande do Norte, Brazil, South America, Tel: + 55 (84) 98876-0206 / 3342-5027; Fax: + 55 (84) 3342-5079; Email: irami.filho@uol.com.br / irami.filho@gmail.com

\section{Abstract}

Background: Severe acute pancreatitis is an acute abdominal disease that possesses a powerful systemic inflammatory response, and can progress quickly, going from the stage of local pancreatic damages to the dysfunction of several organs, with the development of multiple local and systemic complications.

Aim: In this article, a case of splenic perforation by abdominal drain will be described, as a late complication of pancreatic necrosectomy, in a patient with severe acute pancreatitis.

Methods: The information was obtained through data from medical records and photographic registers of the diagnosed methods to which the patient has been submitted, andrevision of medical literature.

Results: F.L.S, female, 54 years old, hospitalized at Health House São Lucas Hospital presenting intense abdominal pain and elevation of pancreatic enzymes. During the hospitalization, the patient developed a sepsis and a new abdominal CT scan showed necrosis covering more than $70 \%$ of the pancreas, associated with the infection of the mentioned necrosis. Following the pancreatic necrosectomy by placement of abdominal drains, the patient presented a splenic perforation by the tubular abdominal drain, resulting in the necessity to adopt conservatory measures to deal with this case.

Conclusion: Therefore, it is possible to observe that there hasn't been any reports of splenic perforation by draining following a pancreatic necrosectomy in the medical literature consulted. Thus, this report constitutes a rare case to the present day. However, there is no way to contraindicate the frequent use of tubular draining, since this is an isolated case and there isn't other data and there aren't reports that analyses this topic in medical literature.

Keywords: Acute necrotizing pancreatitis; Splenic diseases; Drainage; Postoperative complications

\section{Introduction}

Severe acute pancreatitis (SAP) is an acute abdominal disease that possesses a powerful systemic inflammatory response, and can progress quickly, going from the stage of local pancreatic damages to the dysfunction of several organs [1-4]. In most cases, acute pancreatitis (AP) is considered a mild and self-limited disease, but around $20-30 \%$ of all patients with AP develop a case of SAP, with the development of multiple local and systemic complications [5].

The complications associated with AP are divided in local and systemic. The "local" group includes pancreatic pseudocysts, fluid acute peripancreatic collections, and unconfined necrosis; not to mention splenic vein or portal vein thrombosis, colon necrosis and gastric dysfunction [6-9]. These complications must be suspected in case of persistence, or recurrence, of abdominal pain, secondary increase of serum pancreatic enzymes, organic dysfunction intensification, and/or development of clinical signs of sepsis [7-9]. The group of "systemic", there were observations of circulatory and renal alterations, organ failure, or exacerbation of severe pre-existing comorbidities [6-9]. Such complications are responsible for slowing the patient's hospital discharge and determine therapeutic interventions [6,8]. 
Necrotizing pancreatitis is the most fearful development; it is often associated with a reserved prognostic. Interventions are generally indicated to patients with a case of infected pancreatic necrosis and seldom in cases of sterile symptomatic necrosis. Traditionally, the most used approach has been open surgical necrosectomy. Nevertheless, the treatment has been evolving significantly as to using minimally invasive techniques $[3,4,9]$. In this article, a case of splenic perforation by abdominal drain will be described, as a late complication of pancreatic necrosectomy, in a patient with severe acute pancreatitis.

\section{Methods}

The information was obtained through data from medical records and photographic registers of the diagnosed methods to which the patient has been submitted. Having completed the revision of medical literature concerning this topic, through thorough research on the Pubmed/Medline, Scielo, Embase, Scopus and Web of Science databases using the description: "necrotizing pancreatitis", "spleen perforation by tubular drain", "splenic complications in acute pancreatitis", "surgical management in necrotizing pancreatitis". Also, having analyzed published articles in the period between the years 2000 and 2015, written in English, Spanish and Portuguese, we did not find any case of splenic perforation by tubular drain following pancreatic sequestrectomy, or even something similar to this, in all medical literature. Consequently, we can infer that this is a unique case.

\section{Results}

\section{Case Report}

Patient F.L.S, 54 years old, female, admitted to the Health House São Lucas Hospital, Natal/RN-Brazil, presenting high intensity abdominal pain on the upper quadrant, with irradiation on the dorsal region, associated with distension, nausea and vomiting. The patient denied having fever, any sort of bleeding or urinary abnormalities. Patient described an instance of evacuation with softened feces. She also made daily use of $50 \mathrm{mg}$ captopril for arterial hypertension control. The laboratory exams displayed an increase in amylase and lipase, both over 3 times the superior limit of normality. Hence, the patient was diagnosed with severe acute pancreatitis (classified by the Ranson criteria and the tomography index). After her admission in the hospital, the patient was submitted early enteral nutrition through jejunal nasoenteral catheters, as this is protocol when dealing with cases of SAP.

Following the stabilization of the patient's clinical condition and around $48 \mathrm{~h}$ after the diagnosis of the SAP, a CT scan was conducted, which evidenced a grade D acute pancreatitis on the Balthazar classification. Having passed 6 days, a new CT scan displayed an evolution to a grade E (AP). In face of this, the patient remained hospitalized receiving clinic treatment (enteral nutrition, analgesics and venal hydration). On her 20th day of hospitalization, her clinical condition worsened, with the development of diffused abdominal pain, distension, fever, diarrhea and severe edema in inferior limbs. In this occasion, the laboratory exams showed alteration that suggested sepsis. Because of this, a new CT scan was conducted (with contrast), which revealed signs of a SAP, with more than $70 \%$ of pancreatic parenchyma, and two perinecrotic collections which may have suggested an infection; not to mention bilateral pleural effusion.

As a result of the patient's clinical condition, she was submitted to surgical treatment, which consisted in a pancreatic sequestrectomy with the placement of silicon $20 \mathrm{~F}$ tubular (Blake drains), in retrocavity of the epiploon, with the intention to continuously irrigate and wash this area. After the proceeding, the patient was transferred to the Intensive Care Unit (ICU), where she remained for $24 \mathrm{~h}$ and following this, she was moved to the infirmary. Following the surgical proceeding, she remained in continuous irrigation of the pancreas through three drains, via a pressure regime, resulting in an improvement of her clinical condition. Despite the improvement, shortly after one of the washing proceedings, she developed a bacteremia, and there was an observation of a mucocutaneous paleness, fever with shivering and hypotension; resulting in the initiation of an antibiotic therapy.

She developed a progressive improvement, which led to the decision of substituting the enteral diet (offered by the jejunal nasoenteric catheter) with a liquid oral diet test. However, after a few more days of treatment, drainage of enteric content was observed by one of the drains. Therefore, we decided to conduct an upper digestive endoscopy, which evidenced a duodenum-pancreatic fistula. Following this, the enteral diet was suspended, and we initiated a total parenteral nutrition associated with treatment with hyperbaric therapy, culminating in the fistula's spontaneous closure around 28 days after the start of the treatment of this complication.

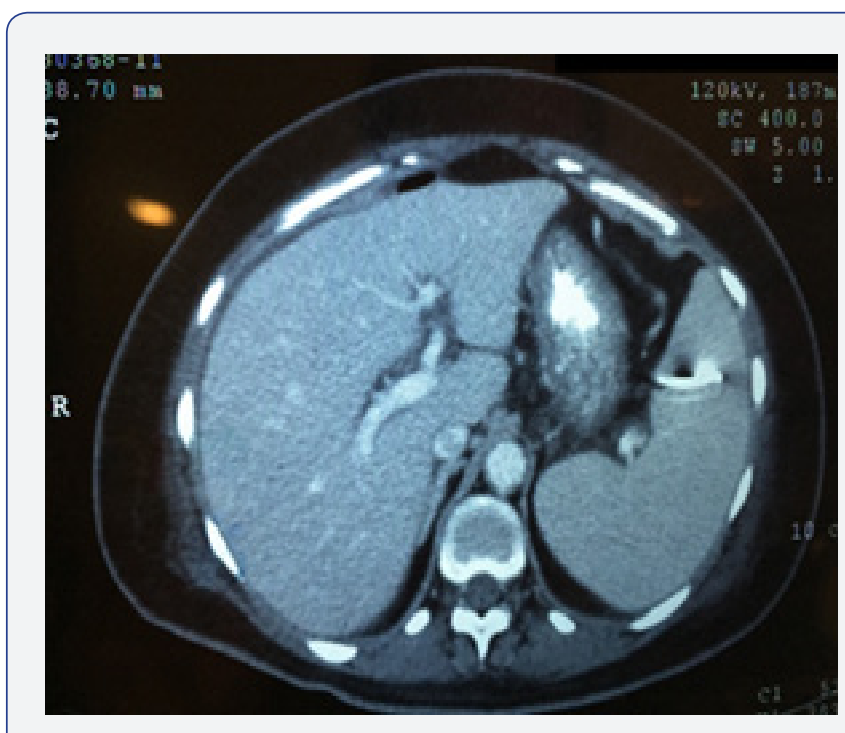

Figure 1: Abdominal CT in axial section, showing abdominal drain transfixing spleen (arrow). 


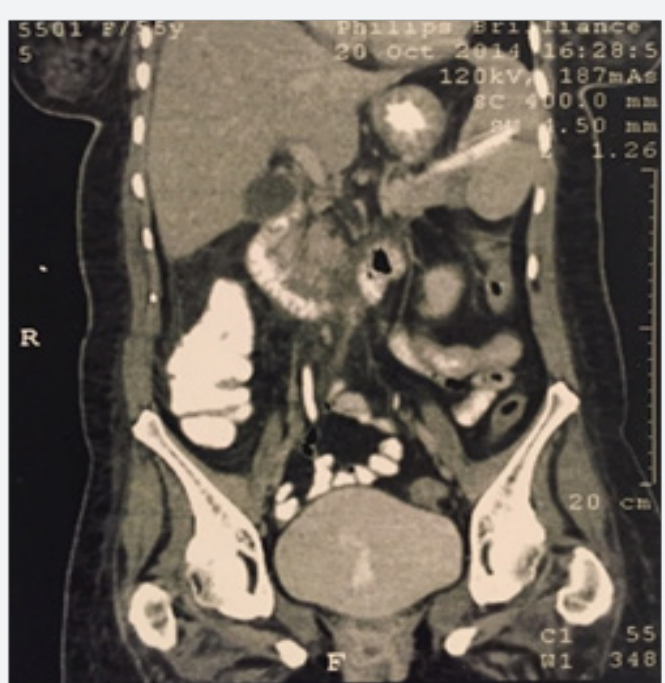

Figure 2: Abdominal CT in coronal section, showing abdominal drain transfixing spleen (arrow), besides peripheral splenic hypotransparent areas that can be related to regions of infarct.

The patient remained hospitalized receiving a conservatory treatment associated with hyperbaric oxygen therapy, showing satisfactory and continuous improvement of her condition and a progressive reduction of the abdominal drain debit, with an improvement of the drained secretion aspect; regardless of showing mild pain on the left upper quadrant and occasional fever (she was receiving antibiotic therapy). She occasionally displayed sudden secretion elimination with a dark maroon color in the abdominal drain of the collecting bag along with a mild and transitory hypotension. The patient was, therefore, submitted to a new total abdomen CT scan (Figures 1 \& 2), with the observation of an abdominal drain where its extremities were in the inferior spleen region, not to mention peripheral splenic hypotransparent areas; which may be related to infarct regions. Because of this, the patient was diagnosed with transfixing lesion of the spleen by the tubular drain.

In the complication treatment, a conservatory measure was chosen, removing the tubular drain on the 5th day after the diagnosis, along with splenic arteriography with the objective of embolization, in case of bleeding. However, there was no bleeding. Following this approach, there was an improvement of the clinic and laboratorial parameters, with the spontaneous output of the abdominal drain. The hospital discharge occurred after 197 days of hospitalization, and the patient did not present any residual symptoms.

\section{Discussion}

The pancreatitis can appear in varied degrees, from a simple form to a more complicated one; and it can also affect other tissues. According to the Atlanta Revision Classification, the AP can be classified in types and degrees of the disease's severity $[6,8]$.
Regarding the types, it is divided in edematous interstitial and necrotizing. The edematous interstitial pancreatitis constitutes $80 \%$ to $90 \%$ of patients with AP. It is a milder form where there isn't a necrosis of the pancreatic parenchyma or peripancreatic parenchyma in image exams, and has a quick resolution. The necrotizing pancreatitis is defined by the presence of necrosis of the pancreatic parenchyma or of the peripancreatic tissues. It is the most aggressive type of AP, associated to the reserved prognostic $[6,8]$. This brings some possible complications in its development, such as: infection, bleeding, alteration of the pancreatic duct and formation of stenosis, and compartmental abdominal syndrome $[3,4,9]$.

Three degrees of classification of the disease's gravity are observed: mild acute, moderated and severe pancreatitis. This classification is based on the presence or absence of the persistent organic failure-verified through the Modified Marshall Score - and local or systemic complications $[6,8,10,11]$. In the mild degree, there isn't any organic failure or local and systemic complications, and generally this is settled within a few days to a week $[6,8]$. The moderated form is associated to transitory organic failure (with a score $\leq 2$ in the Marshall Score in one or more organ systems for less than 48 hours) and/or local complications or exacerbations of pre-existing comorbidities, and in general this resolves in a slower manner, and may require interventions and increases the hospitalization time [6,8].

In the severe form, organic failure occurs in a persistent manner (with a score $\geq 2$ in the Marshall Score in one or more organic systems for more than $48 \mathrm{~h}$ ), which forces the patient to remain hospitalized and some form of intervention $[6,8]$. Systemic complications include splanchnic venous thrombosis, compartmental abdominal syndrome, pseudoaneurysm, acute respiratory distress syndrome and exacerbation of subjacent comorbidities, as a reference of the coronary arterial and chronic pulmonary disease [12]. Most of the severe complications occur within $48 \mathrm{~h}$ after the start of the symptoms. The Ranson criteria can identify several factors which, if positive, can predict a bad prognostic [13].

It's important to remember that the necrotic fluids and tissues may become secondarily infected, resulting in systemic inflammatory response syndrome and sepsis [12]. The most important matter in the management of pancreatic necrosis and peripancreatic necrosis intervention is the adequate moment to do surgery $[3,9]$. At first, the conservative treatment for necrotizing pancreatitis should be the first to be executed [14]. The interventions to drain and/or debride the necrotic tissue are divided in open surgery (transperitoneal laparotomy or retroperitoneal approach with an incision in flank) and minimally invasive (percutaneous proceedings, laparoscopic, retroperitoneal, transmural endoscopy or combined approach) $[3,9]$.

With regards to the adequate moment, it's essential to emphasize that the debridement of the pancreatic necrosis 
less than three weeks of clinical evolution increases the risk of bleeding and other adverse events $[3,9,14]$. Moreover, postpone the intervention allows the separations between necrosis and viable tissue, in a way that if the necrosectomy is executed, the chance of removal of the viable tissue is minimized, allowing a better endocrine and exocrine prognostic $[3,9,15,16]$. In most cases, the sterile acute necrosis doesn't require early intervention (only if there are signs of sepsis). It's only required in a more advanced stage and in the presence of the symptoms (abdominal pain or mechanic bowel obstruction) [3,9,17]. The goal will be to control the infection, through the removal of the necrotic tissue and draining of the inflammatory exudates [18].

The pancreatic necrosis (PN) becomes infected in most cases when it covers more than $50 \%$ of the organ. The diagnostic is given especially when the patients are submitted to CT with contrast, in periods longer than seven days, simplifying the discovery of the necrosis. In case of doubt with regards to infectious condition, a fine needle aspiration (FNA) guided by CT must be executed, followed by Gram staining and microbiologic culture. This method is considered the gold standard of diagnosis [19]. In our case, the puncture was not performed, since there was strong clinical evidence and suggestive CT image of infection in pancreatic tissue.

In case of confirmed infection of pancreatic necrosis, there may be the need for early intervention, aiming to control the infection with the removal of necrotic tissue and preserving the remaining pancreatic tissue [20]. The approach should be done with systemic antibiotics and surgical intervention, such as the laparotomy with pancreatic debridement, accompanied by debridement and washing the peripancreatic tissue $[3,9,17,18]$. After the procedure, the abdomen can be kept in peritoneostomy or be closed and maintained in continuous washing system through calibrous drains [19].

Due to the absence of similar cases in the literature, there is no established cause or frequency of complication of sequestrectomy with abdominal drain in severe acute pancreatitis [20]. Regarding to pancreatic fistulae, are in an abnormal communication between two tissues. They usually arise when there is injury to the main pancreatic duct or one of its branchs [21,22], commonly as complications of procedures as necrosectomy or endoscopic drainage. They are reported mainly posttraumatic pancreatitis, being evidenced by around 2 to 7 days post-trauma observation of serous drainage with increased amylase level (1000-30000u/mL) [23].

There are also reported cases of non-traumatic fistulas resulting from non-surgical treatment of pancreatitis, but mainly as the outcome of a pseudocyst. These fistulas allow more often communication with stomach (one third of the cases), followed by colon and duodenum [24]. Most enteric fistulas by pseudocyst that form in the upper gastrointestinal tract can be treated conservatively and has relatively good prognosis. However fistulas formed in the colon rarely exhibit spontaneous healing and tend to have fatal complications [24].

In the case of infected necrosis, fistulas and bleeding, the treatment must be surgical, and one of the techniques used is the sequestrectomy with drainage per tubular drain [25].

The splenic complications are rare events during the course of acute pancreatitis and have various descriptions, including pseudocyst, subcapsular hematoma, spleen infarction, spleen internal hemorrhage and spleen rupture [26]. Subcapsular hematoma, pseudocysts and ruptured spleen are more common in chronic pancreatitis [26], while splenic infarcts and spleen internal bleeding tend to be more frequent in acute pancreatitis [27]. However no traumatic splenic lesions in acute pancreatitis scenario are rare [28]. To this present date no other splenic injury by tubular drain has been reported.

Visceral perforation, especially perforation of hollow viscera is a known complication of pancreatic necrosectomy; however, this is reported in medical literature as an immediate complication of the procedure. There are no data in the medical literature showing the splenic drilling as a late complication of pancreatic surgical debridement, as well as any relationship between the use of tubular drain with such complication [29].

\section{Conclusion}

Severe acute pancreatitis is a difficult condition to handle, featuring a variety of local and systemic complications, such as acute pseudocyst, pancreatic abscess, net collections, fistulas (pancreaticoenteric and pancreaticopleural), abdominal compartment syndrome, systemic inflammatory response syndrome (SIRS), acute renal failure and pancreatic necrosis, as described in the literature. The complication reported in this case, as previously mentioned, has never been reported in the medical literature as post sequestrectomy pancreatic complication. Thus, despite being a potentially serious complication, we chose to manage the case through a non-invasive therapy with the support of interventional radiology. This approach resulted in a reduction in hospitalization time, reduced likelihood of complications, and consequently optimized time of patient recovery.

\section{References}

1. Jiang L, Jiang S, Ma Y, Zhang M (2015) Can soluble CD73 predict the persistent organ failure in patients with acute pancreatitis. Crit Care Med 43(1): 35-36.

2. Maksimow M, Kyhälä L, Nieminen A, Kylänpää L, Aalto K, et al. (2014) Early prediction of persistent organ failure by soluble CD73 in patients with acute pancreatitis. Crit Care Med 42(12): 2556-2564.

3. Bugiantella W, Rondelli F, Boni M, Stella P, Polistena A, et al. (2015) Necrotizing pancreatitis: A review of the interventions. Int J Surg 1: 163-167.

4. Aranda-Narváez JM, González-Sánchez AJ, Montiel-Casado MC, TitosGarcía A, Santoyo-Santoyo J (2014) Acute necrotizing pancreatitis: Surgical indications and technical procedures. World J Clin Cases 2(12): 840-845 
5. Banks PA, Freeman ML (2006) Practice guidelines in acute pancreatitis. Am J Gastroenterol 101: 2379-2400.

6. Sarr MG (2013) 2012 revision of the Atlanta Classification of acute pancreatitis. Polskie Archiwum Medycyny Wewnętrznej 123(3): 118124.

7. Banks PA, Bollen TL, Dervenis C, Gooszen HG, Johnson CD, et al. (2013) Classification of acute pancreatitis - 2012: revision of the Atlanta classification and definitions by international consensus. Gut 62: 102111.

8. Windsor JA, Johnson CD, Petrov MS, Layer P, Garg PK, et al. (2015) Classifying the severity of acute pancreatitis: Towards a way forward. Pancreatology 15(2): 101-104.

9. Karakayali FY (2014) Management of acute pancreatitis complications. World J Gastroenterol 20(37): 13412-13423.

10. Bakker OJ, Besselink MG, van Santvoort HC, et al. (2010) Dutch Pancreatitis Study Group. A step-up approach or open necrosectomy for necrotizing pancreatitis (PANTER trial). N Engl J Med 362: 14911502.

11. Petrov MS, Shanbhag S, Chakraborty M, Phillips AR, Windsor JA (2010) Organ failure and infection of pancreatic necrosis as determinants of mortality in patients with acute pancreatitis. Gastroenterology 139: 813-820.

12. Khanna S, Nadkarni NA, Vege SS (2013) Splanchnic venous thrombosis and pancreatitis. Pancreas 42(6): 924-931.

13. Chatel P, Ducarme G, Hammel P, Luton D, Maire F (2014) Acute pancreatitis during pregnancy: a review. J Perinatol 34(2): 87-94.

14. Yokoe M, Takada T, Mayumi T, Yoshida M, Isaji S, et al. (2015) Japanese guidelines for the management of acute pancreatitis: Japanese Guidelines 2015. J Hepatobiliary Pancreat Sci 22(6): 405-432.

15. Besselink MG, Verwer TJ, Schoenmaeckers EJ, Buskens E, Ridwan BU, et al. (2007) Timing of surgical intervention in necrotizing pancreatitis. Arch Surg 142(12): 1194-1201.

16. Bhansali SK, Desai SB, Shah SC, Sunawala JD (2003) Infected necrosis complicating acute pancreatitis: experience with 131 cases. Indian J Gastroenterol 22(1): 7-10.

17. Baron TH (2012) International multidisciplinary panel of speakers and moderators. Interventions for necrotizing pancreatitis: summary of a multidisciplinary consensus conference. Pancreas 41(8): 1176-1194.
18. Guimarães-Filho AC, Leal PRF, Maya MCA, Melgaço AS (2009) Pancreatite aguda: etiologia, apresentação clínica e tratamento. Revista Hospital Universitário Pedro Ernesto 8(1): 61-69.

19. Martinez R, Refinetti RA (2010) Pancreatite necro-hemorrágica: atualização e momento de operar. ABCD, Arq Bras Cir Dig 23(2): 122127.

20. Dellinger EP, Tellado JM, Soto NE, Ashley SW, Barie PS, et al. (2007) Early antibiotic treatment for severe acute necrotizing pancreatitis: a randomized, double-blind, placebo-controlled study. Ann Surg 245(5): 674-683.

21. Kozarek RA, Traverso LW (1996) Pancreatic fistulas: etiology, consequences, and treatment. Gastroenterologist 4(4): 238-244.

22. Sabo A, Goussous N, Sardana N, Patel S, Cunningham SC (2015) Necrotizing Pancreatitis: A Review of Multidisciplinary Management. JOP 16(2): 125-135.

23. Foster CE $3^{\text {rd }}$, Lefor AT (1996) General management of gastrointestinal fistulas. Surg Clin North Am 76(5): 1019-1033.

24. Kwon JC (2014) Pancreatic pseudocystocolonic fistula treated without urgical or endoscopic intervention. World J Gastroenterol 20(7): 18821886.

25. Behrns KE, Heider R (2001) Pancreatic pseudocysts complicated by splenic parenchymal involvement: results of operative and percutaneous management. Pancreas 23(1): 20-25.

26. Ernst MD, Mergo PJ, Mortelé KJ, Ros PR, Taylor HM (2001) Splenic and perisplenic involvement in acute pancreatitis: determination of prevalence and morphologic helical CT features. J Comput Assist Tomogr 25(1): 50-54.

27. Bouchier-Hayes D, Cross KS, Leahy AL, Sheehan SJ, Toussi HR (1996) Spontaneous splenic rupture: a rare complication of acute pancreatitis. Br J Surg 83: 632.

28. Kokosis G, Pappas TN, Perez A (2014) Surgical management of necrotizing pancreatitis: An overview. World J Gastroenterol 20(43): 16106-16112.

29. Baron TH (2012) Interventions for necrotizing pancreatitis: summary of a multidisciplinary consensus conference. Pancreas 41: 1176-1194.

\section{Your next submission with Juniper Publishers will reach you the below assets}

- Quality Editorial service

- Swift Peer Review

- Reprints availability

- E-prints Service

- Manuscript Podcast for convenient understanding

- Global attainment for your research

- Manuscript accessibility in different formats

( Pdf, E-pub, Full Text, Audio)

- Unceasing customer service

Track the below URL for one-step submission https://juniperpublishers.com/online-submission.php 